ORIGINAL ARTICLE

\title{
Plasma glucose measurement with the Yellow Springs Glucose 2300 STAT and the Olympus AU640
}

\section{P J Twomey}

Correspondence to: Dr P J Twomey, Department of 'Clinical Biochemistry, The Ipswich Hospital, Heath Road, Ipswich IP4 5PD, UK; Taptwomey@aol.com

Accepted for publication 23 January 2004
Background: Diabetes mellitus is an important diagnosis. New criteria have been defined for impaired glucose metabolism and, accordingly, there is a need for precise and accurate glucose analysis for the correct classification of patients. However, neither the World Health Organisation nor the National Service Framework for Diabetes in England and Wales deal with the associated analytical issues for plasma glucose.

Aims/Methods: To compare two different methods for plasma glucose with respect to European and CLIA '88 quality requirements.

Results: Using several different graphical and statistical techniques, the YSI 2300 STAT was found to be 8.1-8.4\% negatively biased for plasma glucose when compared with the Olympus AU640 method.

Conclusions: Such a large bias would have a large impact on the detection of diabetes mellitus in clinical practice and therefore this method should not be used to make a definitive diagnosis. The bias probably results from the fact that the YSI 2300 STAT uses an aqueous based standard.
$\mathrm{T}$ he World Health Organisation (WHO) ${ }^{1}$ and the American Diabetes Association ${ }^{2}$ have defined the diagnosis of diabetes mellitus in the absence of symptoms by at least two independent estimations of fasting plasma glucose concentration $\geqslant 7.0 \mathrm{mmol} /$ litre, or a random plasma glucose concentration $\geqslant 11.1 \mathrm{mmol} /$ litre, or (WHO only) a two hour post oral glucose tolerance test plasma glucose concentration $\geqslant 11.1 \mathrm{mmol} /$ litre. In the presence of typical symptoms, such as polyuria, polydipsia, or unplanned weight loss, a single plasma glucose meeting the above criteria suffices. In addition, the category of "impaired fasting glycaemia" has been introduced, and is defined as a fasting plasma glucose of 6.1-6.9 mmol/litre. ${ }^{12}$

Accordingly, there are currently two clinical cutoff values for fasting plasma glucose (6.0 and $7.0 \mathrm{mmol} /$ litre). These clinical cutoff values increase the need for precise and accurate results for the correct classification of individuals. This was acknowledged by the WHO when it stated that "the clinician must feel confident that the diagnosis is fully established". ${ }^{1}$ If analyses fail to confirm the diagnosis of diabetes mellitus "it will usually be advisable to maintain surveillance with periodic re-testing until the diagnostic situation becomes clear". ${ }^{1}$ The National Service Framework for Diabetes in England and Wales stated in Standard 2 (identification of people with diabetes) that "the National Health Service will develop, implement and monitor strategies to identify people who do not know they have diabetes". ${ }^{3}$ However, neither of these documents ${ }^{1-3}$ dealt with the associated analytical issues for plasma, which may be crucial in the diagnosis of diabetes mellitus.

\section{"The Olympus system's calibrator is similar to plasma in content and the YSI's glucose calibrator is aqueous glucose"}

Two analytical strategies existed for the diagnosis of diabetes within the Edinburgh Royal Infirmary, depending on whether the patient was seen in primary or secondary care. General practitioners send their specimens via a courier van service to the department of clinical biochemistry, where plasma glucose is measured on one of three Olympus AU640 analysers (Olympus Diagnostic Systerms, Southall, Middlesex, UK) using a hexokinase based methodology. The diabetologists previously diagnosed diabetes mellitus by analysing plasma glucose in line with international recommendations ${ }^{4}$ on a Yellow Springs Instrument (YSI; YSI Inc, Yellow Springs, Ohio, USA) 2300 STAT analyser in the diabetes outpatients department. The YSI STAT 2300 system is capable of analysing both whole blood and plasma specimens (YSI STAT 2300 laboratory manual pages B-2 and B-4; Appendix B, Sample collection and handling: Bl Blood plasma, B2 whole blood), and most specimens analysed on the YSI STAT 2300 in the diabetes outpatients department are whole blood specimens. In addition to using different methods, these analysers used different calibrators: the Olympus system's calibrator is similar to plasma in content and the YSI's glucose calibrator is aqueous glucose. Therefore it was decided to compare these two different systems to ensure comparability between the YSI STAT 2300 and the Olympus AU640 (definitive method).

\section{METHOD}

A systems analysis was performed in accordance with the principles for evaluation of analytical quality specifications to see whether there were substantial differences between the two methods. Sixty seven fluoride oxalate plasma samples were selected from specimens analysed for glucose in the department of clinical biochemistry, Edinburgh Royal Infirmary to ensure a uniform range distribution from $2.5 \mathrm{mmol} /$ litre to $35.0 \mathrm{mmol} /$ litre. These specimens were separated and frozen. After thawing, these samples were subsequently analysed by both methods within two hours of each other. Ethics approval was not required because glucose alone was analysed.

In the Olympus AU640 method, glucose is phosphorylated in the presence of hexokinase and ATP to produce glucose-6-phosphate, which in turn reacts with $\mathrm{NAD}^{+}$to form $\mathrm{NADH}$ and gluconate-6-phosphate in the presence of

Abbreviations: $\mathrm{Cl}$, confidence interval; $\mathrm{WHO}$, World Health Organisation; YSI, Yellow Springs Instrument 
glucose-6-phosphate dehydrogenase. The glucose concentration is proportional to the $\mathrm{NADH}$ induced increase in absorbance at $340 \mathrm{~nm}$ (Olympus System Reagent Glucose OSR 6121 and OSR 6221). The YSI STAT 2300 uses a steady state measurement methodology, where membrane based glucose oxidase catalyses the oxidation of glucose to gluconic acid and hydrogen peroxide. The difference between the sample generated plateau current and the initial baseline current is proportional to the glucose concentration (YSI STAT 2300 laboratory manual page 5-4).

The standards set for total error were the European recommendations based on biological criteria, ${ }^{5}$ which have been calculated at 5.5\% (http://www.westgard.com/europe. htm (last accessed 13 December 2003)), and the CLIA ' $88^{6}$ regulations (table 1). The quality specification for the allowable difference in results between two different methods for the same analyte in one laboratory is that the difference should be less than one third of the within subject biological variation. However, it was decided to compare these methods as if they were from different laboratories because this has more widespread relevance. Should this criterion fail, then the stricter within laboratory criterion would similarly fail. The suggested minimum difference that should be detected at the diabetic diagnostic limit for fasting glucose was $10 \% .{ }^{6}$ Power calculations were performed using a power of $90 \%$, given a significance level of $5 \%$, to ensure that sufficient samples were used in this study to detect this difference. $^{7}$ Analyses were performed over five days to ensure that the method comparison did not become dependent on the performance of the methods in one particular analytical run. Analysis on both analysers occurred within two hours. Internal quality control for both instruments assured that all instruments were acceptable ("in control").

\section{RESULTS}

The data from the five days were comparable. The correlation coefficient $(r)$ was 0.9991 by Deming regression (CBstat package 2.4.l; Kristian Linnet, University Hospital, Aarhus, Denmark), and accordingly linear regression (CBstat package 2.4.1) and a scatter plot were performed (fig 1). The regression equation was YSI $=0.916 \times$ Olympus +0.02 and the $95 \%$ confidence intervals (CI) for the slope and intercept were 0.899 to 0.933 and -0.13 to +0.17 , respectively. The intercept was not significantly different from zero and the slope was significantly different from 1.0 $(\mathrm{p}<0.001)$. The sign sequence of the residuals was visually acceptable. $S_{y . x}$ was estimated to be 0.26 by ordinary linear regression. The percentage difference plot had $>5 \%$ of the data points outside the biological quality specifications and, accordingly, the difference between the two methods is greater than the biological quality specifications (fig 2). The mean difference was $-8.1 \%$, the SD was $2.44 \%$, and the SEM was $0.3 \%$. Accordingly, the $95 \%$ CI for the mean and for the data were $-7.5 \%$ to $-8.7 \%$ and $-3.3 \%$ to $-13.0 \%$, respectively. Using Westgard's method evaluation decision chart approach, ${ }^{8}$ the YSI 2300 also performed poorly (data not provided) when compared with the Olympus AU640 analyser according to the CLIA ' 88 criteria. $^{6}$

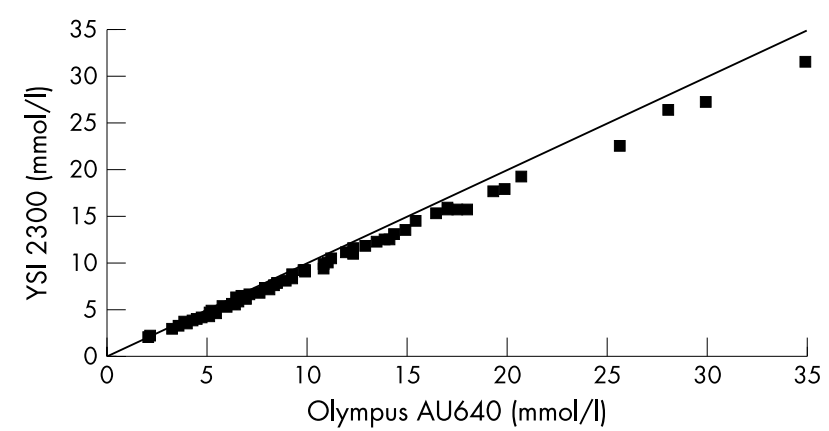

Figure 1 Scatter plot of YSI STAT 2300 plasma glucose (mmol/litre) versus Olympus AU640 plasma glucose ( $\mathrm{mmol} /$ litre) with the line of equality $(y=x)$ added.

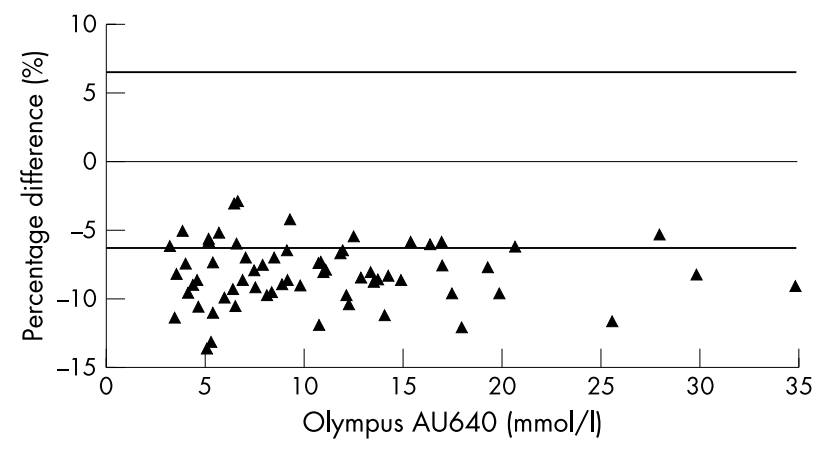

Figure 2 Percentage difference plot of YSI STAT 2300 plasma glucose (mmol/litre) versus Olympus AU640 plasma glucose (mmol/litre) with the biological quality specification limits added.

\section{DISCUSSION}

Irrespective of the method of analysis, the difference between the two methods was such that there was a significant analytical difference between them according to both quality specifications. Using the $95 \%$ CI from the Deming regression analysis, the least amount of bias present was 0.933 or $-6.7 \%$. Thus, a plasma sample with a "true" glucose concentration at the diagnostic cutoff of $7.0 \mathrm{mmol} / \mathrm{litre}$ would have a result of $6.5 \mathrm{mmol} /$ litre (or less) on the YSI, and would therefore be misclassified. According to the biological criteria, the bias at a plasma glucose of $7.0 \mathrm{mmol} /$ litre should be $<0.16 \mathrm{mmol} /$ litre. $^{9}$ Irrespective of the biological and CLIA ' 88 criteria, Stahl et al state that a bias greater than $0.1 \mathrm{mmol} /$ litre at a plasma glucose of $7.0 \mathrm{mmol} /$ litre is unacceptable. ${ }^{10}$ Accordingly, the bias that was found in this method comparison study was clinically unacceptable.

Specificity problems with the YSI methodology are unlikely because the YSI results were not greater than the Olympus results. The lack of constant error (the intercept in the regression equations was not significantly different from zero) and of outliers means that interference and matrix effects in individual plasma samples are unlikely to have given rise to the bias. However, a calibration problem is likely because only the slope in the regression equations was

Table 1 Specifications for total error (TE)

\begin{tabular}{lllll}
\hline Source & TE & TE at $6.0 \mathrm{mmol} / \mathrm{I}$ & TE at $7.0 \mathrm{mmol} / \mathrm{I}$ & TE at $11.1 \mathrm{mmol} / \mathrm{I}$ \\
\hline Biological variation & $5.5 \%$ & $0.33 \mathrm{mmol} / \mathrm{I}$ & $0.39 \mathrm{mmol} / \mathrm{I}$ & $0.61 \mathrm{mmol} / \mathrm{I}$ \\
CLIA '88 & $10 \%$ or & $0.60 \mathrm{mmol} / \mathrm{I}$ & $0.70 \mathrm{mmol} / \mathrm{I}$ & $1.11 \mathrm{mmol} / \mathrm{I}$ \\
& $0.33 \mathrm{mmol} / \mathrm{I}$ & & & \\
\hline
\end{tabular}




\section{Take home messages}

- The YSI 2300 STAT was 8.1-8.4\% negatively biased for plasma glucose when compared with the Olympus AU640 method using both graphical and linear regression techniques

- Such a large bias would have a large impact on the detection of diabetes mellitus in clinical practice, so that this method should not be used to make to a definitive diagnosis

- The bias probably resulted from the fact that the YSI 2300 STAT uses an aqueous based, rather than a serum or plasma based, standard

significantly affected. The YSI uses an aqueous based standard-that is, it is not serum or plasma based-whereas the AU640 uses a serum based calibrator (Olympus system calibrator with total protein by the Biuret method of $54.0 \mathrm{~g} /$ litre). Such a difference in the non-water phases would be expected to produce a plasma glucose that is $6.4 \%$ lower. Chua and $\operatorname{Tan}^{11}$ have previously found that the YSI was only $2 \%$ negatively biased against a Beckman glucose analyser, but they used the same aqueous calibrator for both methods and accordingly my results do not contradict their findings.

"The bias that was found in this method comparison study was clinically unacceptable"

The two methods in this study produced significantly different results. This difference was greater than the biological variation based European criteria ${ }^{9}$ and the CLIA ' 88 criteria, ${ }^{6}$ by both graphical and linear regression techniques. The clinical quality requirement of glucose assays in routine clinical practice is such that the difference between the two methods is too big. ${ }^{10}$ Furthermore, these data question whether the YSI STAT 2300 should be used for measuring glucose in plasma.

\section{REFERENCES}

1 World Health Organisation, Department of Noncommunicable Disease Surveillance. Definition, diagnosis and classification of diabetes mellitus and its complications. Geneva: WHO, 1999, http://whqlibdoc.who.int/hq/ 1999/WHO_NCD_NCS_99.2.pdf (last accessed 13 December 2003).

2 The report of the expert committee on the diagnosis and classification of diabetes mellitus. Diabetes Care 1997;20:1183-97.

3 National Service Framework for Diabetes: Standards. Department of Health, December 2001. http://www.doh.gov.uk/nsf/diabetes/index.htm (last accessed 13 December 2003).

4 Sacks DB, Bruns DE, Goldstein DE, et al. Guidelines and recommendations for laboratory analysis in the diagnosis and management of diabetes mellitus. Clin Chem 2002;48:436-72

5 Fraser CG, Petersen PH, Libeer J-C, et al. Proposals for setting generally applicable quality goals solely based on biology. Ann Clin Biochem 1997;34:8-12.

6 Clinical Laboratory Improvement Amendments of 1988 (CLIA '88), Final Rule. Department of Health and Human Services. Federal Register 1992;57:7002-288.

7 Linnet K. Necessary sample size for method comparison studies based on regression analysis. Clin Chem 1999;45:882-894.

8 Westgard JO. A method evaluation decision chart (MEDx chart) for judging method performance. Clin Lab Sci 1995;8:277-83.

9 Sebastian-Gambao MA Liron-Hernandez FJ, Fuentes-Arderiu X. Intra- and inter-individual biological variability data bank. Eur J Clin Chem Clin Biochem 1997;35:845-52.

10 Stahl M, Jørgensen LGM, Hyltoft Petersen $P$, et al. Optimization of preanalytical conditions and analysis of plasma glucose. 1. Impact of the new $\mathrm{WHO}$ and ADA recommendations on diagnosis of diabetes mellitus. Scand J Clin Lab Invest 2001;61:169-80.

11 Chua KS, Tan IK. Plasma glucose measurement with the Yellow Springs glucose analyser. Clin Chem 1978;24:150-2. 